International Journal of Current Advanced Research

ISSN: O: 2319-6475, ISSN: P: 2319 - 6505, Impact Factor: SJIF: 5.995

Available Online at www.journalijcar.org

Volume 6; Issue 3; March 2017; Page No. 2967-2970

DOI: http://dx.doi.org/10.24327/ijcar.2017.2970.0156

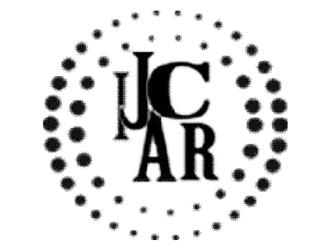

Research Article

\title{
ORAL CANCER: A SYSTEMATIC REVIEW
}

\section{Dharahaas}

Saveetha dental college India

\section{A R T I C L E I N F O}

\section{Article History:}

Received $25^{\text {th }}$ December, 2016

Received in revised form $16^{\text {th }}$ January, 2017

Accepted $18^{\text {th }}$ February, 2017

Published online $28^{\text {th }}$ March, 2017

\begin{abstract}
A B S T R A C T
Oral cavity Squamous Cell Carcinoma (SCC) is common. Whilstthe oral cavity is easily accessible for examination, and althoughtumors of this site cause symptoms at a relatively early stage, a large majority of patients continue to present with late stage disease. Despite readily and widely available treatment,oral cancer carries an overall disease specificrelative mortality of 49\% [1]. In 2007 the World Health Assembly passed a resolution on oral health, urging all member states to "take steps to ensure that prevention of oral cancer is an integral part of national cancer control programs, and to involve oral health professionals or primary health care personnel with relevant training in oral health in detection, early diagnosis and treatment [2]." Despite the multitude of tools marketed to aid in the early diagnosis of oral cancer, there is no general population based screening method shown to reduce mortality associated with oral cancer [3]. Dentists examine their patient's oral cavity during almost every consultation and are in a unique position to both promote primary preventative measures to high risk groups, and aid in early diagnosis and referral of suspicious oral lesions.
\end{abstract}

Copyright $₫ 2017$ Dharahaas. This is an open access article distributed under the Creative Commons Attribution License, which permits unrestricted use, distribution, and reproduction in any medium, provided the original work is properly cited.

\section{INTRODUCTION}

\section{Spectrum of disease}

SCC's make up approximately $90 \%$ of tumors in the oral cavity, with adenocarcinoma/minor salivary tumors accounting for $5 \%$, verrucous carcinoma and lymphoma $2 \%$ each and the remainder being uncommon sarcomas or odontogenic tumours.

\section{Epidemiology}

Oral SCC is the 6th most common cancer globally and its incidence is increasing [4]. The burden of oral cavity SCC varies significantly with cultural risk-taking behaviors worldwide. India, Pakistan, Sri Lanka and Bangladesh have the highest incidence with up to $25 \%$ of all new cancers affecting the oral cavity [5], compared with $6 \%$ in France and $3 \%$ in the UK [6]. The age adjusted incidence is reported from approximately 3.4 to 13.8 per 100,000. Males are more often affected than females by a ratio of $1.5: 1$ [7]. A rising incidence has been noted in patients under 45yrs of age [8], with approximately $6 \%$ of oral cancers now occurring in this age group compared with $3 \%$ in 1973 [9]. The average period for which a patient is aware of an oral lesion prior to bringing it to the attention of their doctor is 3

*Corresponding author: Dharahaas

Saveetha dental college India months [10]. Unfortunately, over $60 \%$ of patients present with stage III or stage IV disease [11], and after treatment can expect only a $45 \%$ and $32 \%$ five-year survival respectively.

\section{Risk factors}

Smoking and alcohol consumption are powerful and synergistic risk factors for the development of oral SCC. Heavy drinkers and smokers have 38 times the risk of abstainers from both products [12]. 20pack-years seems to be the threshold at which a significantly increased risk of cancer is imparted [13,14], and the risk reduces back to baseline 10years after cessation [15]. Betel nut chewing and reverse smoking have a strong causal relationship particularly with buccal and hard palate subsites respectively - this accounts for the extremely high rates of oral SCC in countries where these behaviors are entrenched. UV sunlight is a clear aetiologic factor in lip SCC, which predominantly affects Caucasian males. The role of Human Papilloma Virus (HPV) has been wellis required to confirm it as a strong causal factor for the oral cavity. Immunocompromised individuals have a higher rate of nearly all malignancies and oral SCC is no exception. A number of genetic conditions carry an increased predisposition [18] - these are listed as part of Table 1. Chronic inflammation has long been purported to increase the risk of oral cancer - this may be the way in which candidiasis, syphilis, and chronic trauma from poor dentition contribute to a slight increase in risk of oral cancer. Poor oral hygiene has 
been linked to increased carcinogenesis, the exact mechanism is unclear but it may be relate established in SCC of the oropharynx [16], andwhile a link has been shown to exist with oral cancer also [17], further evidence is required to confirm it as a strong causal factor for the oral cavity. Immunocompromised individuals have a higher rate of nearly all malignancies and oral SCC is no exception. A number of genetic conditions carry an increased predisposition [18] these are listed as part of Table 1. Chronic inflammation has long been purported to increase the risk of oral cancer - this may be the way in which candidiasis, syphilis, and chronic trauma from poor dentition contribute to a slight increase in risk of oral cancer. Poor oral hygiene has been linked to increased carcinogenesis, the exact mechanism is unclear but it may be related to carcinogenic effects from the high burden of polymicrobial oral flora [19].

\section{Potentially malignant disorders}

Use of the term 'Premalignant Lesion' is now discouraged in favour of the phrase "Potentially Malignant disorders [21]." The lesions of most relevance are erythroplakia, leukoplakia, oral lichen planus and submucous fibrosis. Potentially malignant disorders Erythroplakia is defined as a "fiery red patch". These lesions are often symptomatic, have a degree of increased vascularity, and carry a high risk of harbouring dysplasia. All erythroplakic or leukoerythroplakic lesions should be referred for biopsy and or excision. Should mild or moderate dysplasia be confirmed on biopsy, its risk of malignant transformation is $10.3 \%$, with high- grade dysplasia and carcinoma insitu carrying a $24.1 \%$ risk [22].

Leukoplakia is usually asymptomatic and is defined either as a "white plaque that will not rub off" or "a white plaque of questionable risk, having excluded other known diseases or disorders that carry no increased risk for cancer". Confounding benign causes of a white plaque include a frictional lesion from habitual trauma or cheek biting, linea alba (normal white streaks bilaterally along the occlusal line), and leukoedema amongst others [23]. The prevalence of Leukoplakia has been estimated at 2\% [24], although the true rate when the latter of the two above definitions is applied is likely to be a little lower at a more modest $0.5 \%$. The annual malignant transformation rate is estimated to be from $0.3 \%$ [25] to $1 \%$. It is generally accepted that referral for biopsy or excision is warranted for these lesions.

Lichen Planus is an oral autoimmune condition with a number of morphological variants including reticular (fine white lacy lines), erosive (shallow ulcers), atrophic (thinned erythematousmucosa), and bullous (fluid filled vesicles). It can be symptomatic typically with a burning feeling or hypersensitivity of the affected mucosa. There remains debate as to its status as a potentially malignant condition. It is generally accepted that its risk of malignant transformation is below $1 \%$ per year [26]. A patient with lesions such as these should be referred to a specialist for biopsy.

Submucous Fibrosis causes progressive trismus due to fibrosis of the connective tissues of the cheeks. It is strongly associated with betel nut/tobacco chewing and it is likely that the use of these carcinogens give it an association with oral cancer. The rate of malignant transformation is estimated at $0.5 \%$ per year [27].

\section{Screening and early detection}

Screening for a disease implies the application of a test to an asymptomatic population with the aim of detecting disease at an early stage. This disease must be a significant public health issue, and the natural history and management of the disease must be well understood such that improved outcomes can be expected when treated at an early stage. Furthermore the test itself and any morbidity associated with further investigation of false positives must be acceptable [28].

The established screening test for oral SCC is clinical examination - with biopsy and histopathological assessment being the gold standard to confirm the diagnosis. Oral cavity examination has been demonstrated in a meta-analysis by Downer et al [29] to have a sensitivity of 0.84 and a specificity of 0.97 . For comparison they note that both mammography and cervical screening programmesshare an approximatesensitivity and specificity of 0.8 and 0.98 respectively. Oral examination is simple, takes only a few minutes, requires minimal equipment, is non-invasive and can be performed by a wide range of health professionals.

For widespread structured screening to be instituted it must be shown to not only be of value in reducing morbidity and mortality, but also to be cost effective. Sankaranarayanan et al [30] published a hallmark paper in the Lancet in 2005 in which they assessed their oral cancer screening programme when applied to a prospective cohort of over 87,000 individuals over the age of 35.They found no significant effect on the disease specific mortality when applied to the general population. However, subgroup analysis of smokers and/or drinkers showed a reduction in mortality of $43 \%$ and $22 \%$ in men and women respectively. A subsequent paper [31] found this approach to be cost effective - albeit in India where there is a high rate of oral cancer. There are no similar trials in a low prevalence society, howeversimulation modeling has shown that a screening oral examination in high-risk individuals in a western population may also be cost effective

\section{CONCLUSION}

Oral SCC occurs typically in males from a low socioeconomic background who smoke and consume alcohol. Patients unfortunately continue to present with late stage disease. An oral screening examination is a simple noninvasive test to apply, has a comparable sensitivity and specificity to that of the well established cervical and breast cancer screening programs, and is felt to probably be cost effective when applied to high-risk individuals in western society.

In the absence of any formal screening program being introduced, dentists and GP's can best serve these high-risk patients by performing regular opportunistic oral examination and educating these patients to increase their awareness of the early signs and symptoms of oral cancer. Oral medicinesurgeons must improve efforts to educate Dentists and GP's to ensure they feel adequately equipped and supported to perform this role. If a suspicious lesion found Immediate referral or further investigation and subsequent treatment is advised. 


\section{References}

1. 1AJCC Cancer staging manual 7th edition. 2010; 33

2. World Health Organization Oral health: action plan for promotion and integrated disease prevention (60th world health assembly resolution A16), Geneva, WHO. 2007.

3. Speight PM, Downer MC, Zakrzewska J. Screening for oral cancer and precancer. A report of the UK working group on screening for oral cancer and precancer. Community Dent Health. 1993; 10: 1-89.

4. Ferlay J, Pisani P, Parkin DM. GLOBOCAN 2002. Cancer incidence, mortality and prevalence worldwide. IARC Cancer Base (2002 estimates). Lyon: IARC Press. 2004.

5. IARC. Cancer incidence in five continents. vol $1 \mathrm{X}$.

6. Brocklehurst P, Kujan O, Glenny AM, Ogden G, Shepherd S, Glenny AM. et al. Screening programmes for the early detection and prevention of oral cancer. Cochrane Database of Systematic Reviews. 2010.

7. Warnakulasuriya S. Global epidemiology of oral and oropharyngeal cancer. Oral Oncol. 2009; 45: 309-316.

8. Warnakulasuriya S, Mak V, Möller H. Oral cancer survival in young people in South East England. Oral Oncol. 2007; 43: 982-986.

9. Llewellyn CD, Johnson NW, Warnakulasuriya KA. Risk factors for squamous cell carcinoma of the oral cavity in young people--a comprehensive literature review. Oral Oncol. 2001; 37: 401-418.

10. McGurk M, Chan C, Jones J, O'regan E, Sherriff M. Delay in diagnosis and its effect on outcome in head and neck cancer. Br J Oral Maxillofac Surg. 2005; 43: 281-284.

11. Lingen MW, Kalmar JR, Karrison T, Speight PM. Critical evaluation of diagnostic aids for the detection of oral cancer. Oral Oncol. 2008; 44: 1022.

12. Blot WJ, McLaughlin JK, Winn DM, Austin DF, Greenberg RS, PrestonMartin S. Smoking and drinking in relation to oral and pharyngeal cancer. Cancer Res. 1988; 48: 3282-3287.

13. Hashibe M, Brennan P, Benhamou S, Castellsague $\mathrm{X}$, Chen C, Curado MP. Alcohol drinking in never users of tobacco, cigarette smoking in never drinkers, and the risk of head and neck cancer: pooled analysis in the International Head and Neck Cancer Epidemiology Consortium. J Natl Cancer Inst. 2007; 99: 777-789.

14. IARC Working Group on the Evaluation of Carcinogenic Risks to Humans. Tobacco smoke and involuntary smoking. IARC Monogr Eval Carcinog Risks Hum. 2004; 83: 1-1438.

15. Warnakulasuriya S, Sutherland G, Scully C. Tobacco, oral cancer, and treatment of dependence. Oral Oncol. 2005; 41: 244-260.

16. Ang KK, Harris $\mathrm{J}$, Wheeler R, Weber R, Rosenthal DI, Nguyen-Tân PF. Human papillomavirus and survival of patients with oropharyngeal cancer. N Engl J Med. 2010; 363: 2435.

17. Scully C. Oral cancer; the evidence for sexual transmission. Br Dent J. 2005; 199: 203-207.
18. Prime SS, Thakker NS, Pring M, Guest PG, Paterson IC. A review of inherited cancer syndromes and their relevance to oral squamous cell carcinoma. Oral Oncol. 2001; 37: 1-16.

19. Bloching $M$, Reich W, Schubert J, Grummt T, Sandner A. The influence Central of oral hygiene on salivary quality in the Ames Test, as a marker for genotoxic effects. Oral Oncol. 2007; 43: 933-939.

20. Zheng TZ, Boyle P, Hu HF, Duan J, Jian PJ, Ma $\mathrm{DQ}$, et al. Dentition, oral hygiene, and risk of oral cancer: a case-control study in Beijing, People's Republic of China. Cancer Causes Control. 1990; 1: 235-241.

21. Warnakulasuriya S, Johnson NW, van der Waal I. Nomenclature and classification of potentially malignant disorders of the oral mucosa. $J$ Oral Pathol Med. 2007; 36: 575-580

22. Mehanna HM, Rattay T, Smith J, McConkey CC. Treatment and followup of oral dysplasia - a systematic review and meta-analysis. Head Neck. 2009; 31: 1600-1609.

23. Van Der Waal I. Potentially malignant disorders of the oral and oropharyngeal mucosa; terminology, classification and present concepts of management. Oral Oncol. 2009; 45: 317-323.

24. Petti S. Pooled estimate of world leukoplakia prevalence: a systematic review. Oral Oncol. 2003; 39: 770-780

25. Gupta PC, Mehta FS, Daftary DK, Pindborg JJ, Bhonsle RB, Jalnawalla PN. Incidence rates of oral cancer and natural history of oral precancerous lesions in a 10-year follow-up study of Indian villagers. Community Dent Oral Epidemiol. 1980; 8: 283-333

26. Gandolfo S, Richiardi L, Carrozzo M, et al. Risk of oral squamous cell carcinoma in 402 patients with oral lichen planus: a follow-up study in an Italian population. Oral Oncol. 2004; 40:77-83

27. Murti PR, Bhonsle RB, Pindborg JJ, Daftary DK, Gupta PC, Mehta FS. Malignant transformation rate in oral submucous fibrosis over a 17year period. Community Dent Oral Epidemiol. 1985; 13: 340-341

28. Wilson JM, Jungner YG. Principles and practice of screening for disease. Public health paper number 34. WHO, Geneva, Switzerland. 1968.

29. Downer MC, Moles DR, Palmer S, Speight PM. A systematic review of test performance in screening for oral cancer and precancer. Oral Oncol. 2004; 40: 264-273.

30. Sankaranarayanan R, Ramadas K, Thomas G, Muwonge R, Thara S, Mathew B. Effect of screening on oral cancer mortality in Kerala, India: Cite this article a cluster-randomised controlled trial. Lancet. 2005; 365: 1927-1933

31. Subramanian S, Sankaranarayanan R, Bapat B, Somanathan T, Thomas G, Mathew B. Costeffectiveness of oral cancer screening: results from a cluster randomized controlled trial in India. Bull World Health Organ. 2009; 87: 200-206.

32. Speight PM, Palmer S, Moles DR, Downer MC, Smith DH, Henriksson M. The cost-effectiveness of 
screening for oral cancer in primary care. Health Technol Assess. 2006; 10: 1-144, iii-iv.

33. Macpherson LM, McCann MF, Gibson J, Binnie VI, Stephen KW. The role of primary healthcare professionals in oral cancer prevention and detection. Br Dent J. 2003; 195: 277-281.

34. Haughney MG, Devennie JC, Macpherson LM, Mason DK. Integration of primary care dental and medical services: a three-year study. $B r$ Dent J. 1998; 184: 343-347

35. Gandolfo S, Pentenero M, Broccoletti R, Pagano M, Carrozzo M, Scully C. Toluidine blue uptake in potentially malignant oral lesions in vivo: clinical and histological assessment. Oral Oncol. 2006; 42: 89-95.

36. Gray MGL, Burls A, Elley K. The clinical effectiveness of toluidine blue dye as an adjunct to oral cancer screening in general dental practice. A West Midlands Development and Evaluation Service Report. 2000
37. Fist S. The oral brush biopsy: separating fact from fiction. Oral Surg Oral Med Oral Pathol Oral Radiol Endod. 2003; 96: 654-655.

38. Eisen D. Brush biopsy 'saves lives'. J Am Dent Assoc. 2002; 133: 688, 690, 692.

39. Kerr AR, Sirois DA, Epstein JB. Clinical evaluation of chemiluminescent lighting: an adjunct for oral mucosal examinations. J Clin Dent. 2006; 17: 59-63.

40. De Veld DC, Witjes MJ, Sterenborg HJ, Roodenburg JL. The status of in vivo autofluorescence spectroscopy and imaging for oral oncology. Oral Oncol. 2005;41: 117-131.

41. Watanabe A, Tsujie H, Taniguchi M, Hosokawa M, Fujita M, Sasaki S. Laryngoscopic detection of pharyngeal carcinoma in situ with narrowband imaging. Laryngoscope. 2006; 116: 650-654.

\section{Please cite this article in press as:}

Dharahaas (2017), 'Oral cancer: a systematic review', International Journal of Current Advanced Research, 6(3), pp. 2967-2970. http://dx.doi.org/10.24327/ijcar.2017. 2970.0156 